\title{
The Reality of Trafficked People's Access to Technology
}

\author{
Jessica Elliott* and Kieran McCartan ${ }^{\dagger}$
}

\begin{abstract}
Human trafficking is a global phenomenon. The UK is predominantly, although not exclusively, a destination country for trafficked persons. There is a lack of empirical research and data available which addresses the reality of access by trafficked persons to certain means of communication (internet, mobile phone technology or a PC); therefore any attempts to use these mediums to assist or identify trafficked individuals are based on speculation rather than empiricism. This research through semi-structured interviews with professionals who work with trafficked people or in related fields (for example, immigration agencies, police, victim support, therapists) $(n=14)$, identified via snowball and purposive sampling, aims to establish the level of access trafficked persons/putatively trafficked persons have to communication technology. This research identifies a general understanding of trafficked people's access to communication technology; how access to this technology either helps or hinders them escape their current situation; and, consequentially, how technology could assist in responding to trafficking.
\end{abstract}

\section{Keywords Trafficking; Technology; Professional understandings}

Human trafficking is a global issue with a national and international impact. ${ }^{1}$ It is a multi-faceted and multi-purpose crime which includes, among other offences, the facilitation of sexual or labour exploitation of adults as well as children. ${ }^{2}$ Furthermore, human trafficking is large scale and lucrative, ${ }^{3}$ and is estimated to generate revenues ranging from $\$ 12$ billion, ${ }^{4}$ to $\$ 31$ billion. ${ }^{5}$ Estimates as to the magnitude of the human trafficking phenomenon envisage several million victims being trafficked worldwide annually. ${ }^{6}$ It has been estimated that 120,000 women

* Senior Lecturer in Law, University of the West of England; e-mail: Jessica.Elliott@ uwe.ac.uk.

+ Senior Lecturer in Criminology, University of the West of England; e-mail: Kieran. Mccartan@uwe.ac.uk.

1 S. Skrobanek, N. Boonpakedi and C. Janthakeero, The Traffic in Women: Human Realities of the International Sex Trade (Zed Books: London, 1997); A. Aronowitz, 'Smuggling and Trafficking in Human Beings: The Phenomenon, the Markets that Drive It and the Organisations that Promote It' (2001) 9 European Journal of Criminal Policy and Research 163; United Nations Office on Drugs and Crime, Human Trafficking FAQs (2012), available at http://www.unodc.org/unodc/en/human-trafficking/ faqs.html, accessed 15 April 2013.

2 S. Drew, 'Human Trafficking: A Modern Form of Slavery?' (2002) 4 European Human Rights Law Review 481; S. Scarpa, Trafficking in Human Beings: Modern Slavery (Oxford University Press: Oxford, 2008).

3 V. Malarek, The Natashas: Inside the New Global Sex Trade (Arcade Publishing: New York, 2004) 5.

4 Ibid.

5 Europol, Annual Report 2009, available at https://www.europol.europa.eu/, accessed 15 April 2013.

6 International Organisation for Migration, http://www.iom.int/jahia/Jahia/pid/1, accessed 15 April 2013.

The Journal of Criminal Law (2013) 77 JCL 255-273 
and children are trafficked specifically into Western Europe each year. ${ }^{7}$ In 2003, government estimates envisaged around 4,000 sex trafficking victims being present in the UK at any one time. ${ }^{8}$ Due to the inherently clandestine nature of human trafficking, it is impossible to arrive at a more definite figure, and a lack of verifiable data means that these estimates should be treated with caution. Consequently, these figures may be as close as it is possible to get to a realistic picture of the magnitude of trafficking globally and in the UK.

The most recent comprehensive and internationally accepted definition of human trafficking is contained within several legal instruments: the United Nations Protocol to Prevent, Suppress and Punish Trafficking in Persons, Especially Women and Children, Supplementing the United Nations Convention Against Transnational Organized Crime 2000 (UN Trafficking Protocol); ${ }^{9}$ the Council of Europe Convention on Action Against Trafficking in Human Beings 2005 (Council of Europe Trafficking Convention) $;{ }^{10}$ and the Directive of the European Parliament and of the Council on preventing and combating trafficking in human beings and protecting its victims 2011 (2011 Trafficking Directive). ${ }^{11}$ The definition provided within these respective instruments is as follows:

'Trafficking in persons' shall mean the recruitment, transportation, transfer, harbouring or receipt of persons, by means of the threat or use of force or other forms of coercion, of abduction, of fraud, of deception, of the abuse of power or of a position of vulnerability or of the giving or receiving of payments or benefits to achieve the consent of a person having control over another person, for the purpose of exploitation. (UN Trafficking Protocol, Article 3)

Since its publication in 2000, the above definition has been replicated (Council of Europe Trafficking Convention, Article 4) as well as been built upon to include the additional aspect of begging as a form of 'forced labour or services' (2011 Trafficking Directive, Article 2) this addition being a product of 'Operation Golf' which led to the identification of

7 European Commission, 'Daphne: An EU Response to Combat Violence towards Children, Young People, and Women', available at http://ec.europa.eu/justice_home/ daphnetoolkit/files/others/illustrative_projects/15_streets_en.pdf, accessed 16 April 2013; F. Laczko, International Organization for Migration, 'Data Insight: Human Trafficking: The Need for Better Data' (November 2002), available at http://www. migrationinformation.org/Feature/display.cfm?ID=66, accessed 15 April 2013.

8 Joint Committee on Human Rights Twenty-Sixth Report (Session 2005-6) [78/205], 'The Scale and Nature of Human Trafficking in the UK', available at http: //www.publications.parliament.uk/pa/jt200506/jtselect/jtrights/245/24507.htm\#n109, accessed 15 April 2013.

9 Protocol to Prevent, Suppress and Punish Trafficking in Persons, Especially Women and Children, Supplementing the United Nations Convention Against Transnational Organized Crime, Art. 3 (adopted November 2000 by United Nations General Assembly Resolution A/RES/55/25, entered into force 25 December 2003).

10 Council of Europe Convention on Action against Trafficking in Human Beings and its Explanatory Report, Art. 4 (adopted 3 May 2005, entered into force 1 February 2008) Warsaw, 16.V.2005, Council of Europe Treaty Series-No. 197).

11 Directive 2011/36/EU of the European Parliament and of the Council of 5 April 2011 on preventing and combating trafficking in human beings and protecting its victims, and replacing Council Framework Decision 2002/629/JHA [2001] OJ L $101 / 1$, art. 2 . 
children being trafficked for forced criminality. ${ }^{12}$ These instruments which contain the trafficking definition(s) form the international legal anti-trafficking regime, and establish the obligations which are placed upon states which are subject to their provisions.

The trafficking definition adds the caveat that ' $[t]$ he consent of a victim of trafficking in persons to the intended exploitation . . . shall be irrelevant where any of the means (such as coercion, force etc.) have been used'. Consequently, it can be seen that elements of the offence such as coercion or threats are an integral part of this definition (except where the victim is under 18 as the presence of coercion, etc. is not a requirement as regards minors).

Trafficking is criminalised through a plethora of provisions in the UK, many of which can be found in the Sexual Offences Act 2003 (SOA) and the Asylum and Immigration (Treatment of Claimants, etc.) Act 2004. Trafficking for sexual exploitation (into, out of, and within the UK) is specifically addressed by SOA ss 57-59. However, these provisions do not stand alone and must be taken in conjunction with another/others. For example, s. 57 provides for the basic criminal offence of trafficking into the UK for sexual exploitation, but also refers to the commission of, or at least the intent to commit, one of the 'relevant offences' contained within Part 1 of SOA, including rape (s. 1) or controlling prostitution for gain (s. 53). Consequently, it can be seen that trafficking-as internationally and domestically understood-is by definition a nonconsensual process characterised by coercion and control on the part of the trafficker(s).

In many instances, human trafficking illustrates the link between migration outflow from impoverished regions, and subsequent exploitation of the migrant by those involved in the trafficking process. Many trafficking situations will begin on a consensual footing. ${ }^{13}$ Consequently, the role of 'push' factors, such as economic hardship, in the global trade in human beings should not be underestimated, as trafficking is contextual and frequently takes place against a backdrop of poverty and lack of opportunity in the origin state. ${ }^{14}$ Victims tend to originate from countries with unstable economies, or developing countries where the feminisation of poverty is evident, and are moved to richer, more stable predominantly Western destination countries, ${ }^{15}$ although this is not exclusively the case. The trafficking patterns largely follow a south to

12 European Commission, Operation GOLF-A UK and Romanian Joint Investigation Tackling Romanian Organised Crime and Child Trafficking (2012), available at http://ec. europa.eu/anti-trafficking/entity.action;jsessionid=JQFsRZLJCtf51Q2lyJpl2mF2hrLNCpCLLY TNf12BGGHwJfL91Qj2!-656776111?path=EU+Projects\%2FISEC_2007_FPA_C1_034, accessed 16 April 2013.

13 Aronowitz, above n. 1.

14 UNICEF, UNOHCHR, OSCE, ODIR, 'Trafficking in Human Beings in Southeastern Europe' (2004), available at http://www.iom.md/materials/1_traff_human_beings_se.pdf, accessed 15 April 2013.

15 Ibid.; European Commission, 'Trafficking in Women-The Misery Behind the Fantasy: From Poverty to Sex Slavery-A Comprehensive European Strategy', 8 March 2001, available at http://www.unhcr.org/refworld/category,POLICY,EUCOM MISSION,,,4693aa7f2,0.html, accessed 15 April 2013. 
north and east to west flow, yet are amenable to change according to market forces of supply and demand.

The influence and involvement of Organised Crime Groups (OCGs) are also significant factors in the continuation of trafficking activity, as this phenomenon continues to turn substantial profits which are seen to far outweigh the risk associated with the criminal behaviour. Traffickers can be highly organised and sophisticated, and respond to antitrafficking measures and adapt their methods and route accordingly. ${ }^{16}$

Warnath observes that ' $[\mathrm{t}$ ]rafficking of women and children is not a new problem ... what is new is the growing involvement of organised crime and the increasing sophistication of its methods' ${ }^{17}$ This is also true of the 'technological revolution' inherent in present-day traffickingrelated activities. New developments in technology, as well as in media, have allowed us to control and prevent interpersonal violence, slavery and trafficking. The same advancements, paradoxically, allow the perpetrators to adapt their offending behaviour. ${ }^{18}$ Often benign technological software and hardware developments can be used by offenders in general, and traffickers specifically, in a predatory and/or deviant way which is completely divorced from their original intent, drawing parallels between the unpredictable nature of risk in the modern society. ${ }^{19}$ This means that we may not always be aware of how offenders, and trafficker's specifically, will use new technology in their practices and as such this renders it difficult for law enforcement agencies to stay one step ahead.

The development of smartphones (especially the iPhone and Blackberry), which are more akin to laptops than traditional phones, has opened up the facilitation of abusive practices in a new and adaptable way to the general public. The potential impact of mobile phone-related, or at least facilitated, offending is large ${ }^{20}$ and will only increase given that mobile phone, specifically smartphone, ownership is on the rise. ${ }^{21}$ Therefore mobile phone technology, especially high-end smartphone

16 Europol, Crimes against the Person Unit, 'Trafficking of Women and Children for Sexual Exploitation in the EU: The Involvement of Western Balkans Organised Crime', Public Version (2006), available at http://www.europol.europa.eu/publications/ Serious_Crime_Overviews/Western_Balkans_THB_Threat_Assessment.PDF, accessed 15 April 2013.

17 S. Warnath, 'Trafficking of Women and Children: The Future Direction of United States Policy. Report of the US-EU Trafficking in Women Seminar', L'Viv, Ukraine, 9-10 July, 1998, 63-6.

18 K. F. McCartan and R. McAlister, 'Mobile Phone Technology and Sexual Abuse' (2012) 21 Information Communications $\theta$ Technology Law 257.

19 P. Taylor-Gooby and J. Zinn, Risk and Social Science (Oxford University Press, Oxford, 2006); A. Giddens, Modernity and Self-identity; Self and Society in the Late Modern Age (Polity Press: Cambridge, 1991); F. Fuerdi. Culture of Fear: Risk-taking and the Morality of Low Expectation (Continuum: New York and London, 2002); U. Beck, Risk Society: Towards a New Modernity (Polity Press: Cambridge, 1992); J. Scourfield and L. Walsh, 'Risk, Reflexivity and Social Control in Child Protection: New Times or the Same Old Story?’ (2003) 23 Critical Social Policy 398.

20 BBC News, 'Over 5 billion mobile phone connections worldwide’, 9 July 2010 , available at http://www.bbc.co.uk/news/10569081, accessed 15 April 2013.

21 Mobithinking.com, Global mobile statistics 2012 Home, available at: http://mobi thinking.com/mobile-marketing-tools/latest-mobile-stats, accessed 15 April 2013. 
technology, has a direct impact upon crime nationally and internationally, as well as specifically upon certain types of offending (i.e. interpersonal violence and trafficking).

The mediums which traffickers use to make contact with and recruit victims are constantly evolving, as are the methods of advertising victims for purchase by 'clients' or 'johns'. One way in which this transpires is through mobile phone use, with third parties facilitating sexual contact with victims, either through trafficking or prostitution. ${ }^{22}$ This adaptation of modern technologies by trafficking networks is unsurprising, reflecting similar adaptations in other areas of sexual violence. ${ }^{23}$ Due to the growing use of the internet to facilitate trafficking, it is argued that sex trafficking itself has moved online ${ }^{24}$ and the use of internet technology in this respect only exacerbates the problem of trafficking as it increases the potential for individuals to be exploited regardless of geographical boundaries. Latonero ${ }^{25}$ has identified that technology provides ample opportunities for advertisement (of victims), and furthermore that the extent to which technology is used is unclear. Case law indicates that online networking sites such as Craigslist and Myspace have been used for trafficking, as well as Facebook. ${ }^{26}$

While it seems clear that traffickers are increasingly taking advantage of technology in order to facilitate trafficking in humans, a more recent approach seeks to tackle this matter from the other side, and questions whether technology (mobile phone, internet) can in fact be used in the fight against trafficking. ${ }^{27}$ This can, for example, be through the use of mobile phone networks providing additional information regarding their client's mobile phone use, collating recording of numbers, texts and internet usage. ${ }^{28}$ Furthermore, with material being saved to mobile phones in the same way as computers, it means that deleted information (i.e. files, pictures, internet sites visited) can be easily retrieved. This means that law enforcement can use this information to build a case against an alleged offender.

Recent initiatives include the development of a mobile phone application which provides for consumers (i.e. mobile phone users) to access information regarding companies who demonstrate a 'zero tolerance for

22 A. Topping, 'Child sex trafficking in UK on the rise with even younger victims targeted', 17 January 2011, Guardian, available at http://www.guardian.co.uk/society/ 2011/jan/17/child-trafficking-uk-rise, accessed 15 April 2013.

23 M. Taylor and E. Quayle, Child Pornography: An Internet Crime (Routledge: Brighton, 2003).

24 E. Kunze, 'Sex Trafficking Via the Internet: How International Agreements Address the Problem and Fail to Go Far Enough' (2010) 10 Journal of High Technology Law 241.

25 M. Latonero, 'Human Trafficking Online: The Role of Social Networking Sites and Online Classified's' (2011), available at http://technologyandtrafficking.usc.edu/report, accessed 15 April 2013.

26 A. Kloer, 'Teen Prostitution Ring Operation on Facebook Gets Busted', Change.org News, 2 February 2010.

27 See Latonero, above n. 25.

28 See McCartan and McAlister, above n. 18. 
forced labor' approach. ${ }^{29}$ Furthermore, there was the development and launch of a Stop Human Trafficking App Challenge which involved the innovative design of anti-trafficking mobile phone technology apps to specifically target trafficking in Russia. With respect to this initiative, it was observed that '[t]raffickers in the region are increasingly using mobile technology to lure vulnerable people into modern-day slavery. The Stop Human Trafficking App Challenge makes mobile technology part of the solution'.$^{30}$ The apps were to be judged according to various criteria, including, inter alia, the provision of services to victims. The latter comprises the central concern of this research. Similarly, there has been the development of the 'Safe Trip' app, which allows for potential migrants to enter some personal information online prior to setting off so that upon arrival they can indicate that either they have arrived safely or that an emergency has occurred. ${ }^{31}$ Developments of this kind raise the issue of the viability of the use of mobile phone technology to combat trafficking and aid victims in escaping from their situation. Despite the potential positive impact of these mobile phone apps and developments, care needs to be taken so that any potential for harm to occur to victims as a result of their use, as well as considerations regarding the viability of law enforcement, are optimised. ${ }^{32}$ Also, given the global nature of human trafficking any developments in mobile phone security, policing, policy and practice need to be embraced internationally.

In order to determine the potential viability of the use of mobile phone technology (by victims) to help combat trafficking and aid the victims, it is necessary to determine the level and frequency of access to mobile phones that trafficked victims actually have. However, there is currently no solid empirical data in this area. The aims of this research are:

- to determine whether trafficked victims and putatively trafficked persons have any access to mobile phone and internet technology; and

- to determine what level of access they report having.

The research therefore seeks to establish whether mobile phone and internet technology may be effectively utilised in the fight against trafficking, and as a starting point this necessarily requires that we establish whether victims/putative victims even have access to such mediums of communication.

29 See Latonero, above n. 25.

30 A. Padget, 'NetHope, USAID and DNA Foundation Launch Mobile Trafficking App Contest in Russia and the Region', Press Release, 14 June 2011, available at http:// nethope.org/media/press-room/nethope-usaid-and-dna-foundation-launch-mobile-traffickingapp-contest-in- $r$, accessed 15 April 2013.

31 Guardian Hactivate Event, 18 and 19 June 2011, available at http://blog.bluevia.com/ 2011/06/22/guardian-hactivate-event-saturday-18th-and-sunday-19th-junel, accessed at 15 April 2013.

32 See Latonero, above n. 25. 


\section{Method}

\section{Design}

This research is qualitative in nature, consisting of a series of semistructured interviews $(n=14)$ with a broad range of professionals who work in and around the area of preventing/responding to human trafficking in the UK, as well as in related fields. The semi-structured interviews allow the participants to give in-depth, reflective and personalised responses. ${ }^{33}$

\section{Sampling and participants}

The research focuses on professionals who work in and around the area of preventing as well as responding to people trafficking in and around the UK. Initially the researchers decided upon a purposive sampling technique, ${ }^{34}$ with an internet search for relevant participants (i.e. online newspapers archives were examined for reporters who had worked on child sexual abuse stories; psych-info and web of knowledge, as well as university web pages, were used to find academics who worked in this field; and the details of 'First Responders' (i.e. those who are formally recognised by the Serious Organised Crime Agency as being the first point of call as regards the identification of trafficked victims) were located through online searches). This was then followed up by looking at the potential participants' employers or companies' websites, or in some cases their personal websites. However, that approach did not work with all the participants (i.e. when contacting members of the police, probation or therapists, their employers, agencies or units were contacted and the relevant participant was suggested or volunteered). Upon closer inspection some potential participants where disregarded because they did not work directly in the field or were not knowledgeable enough to be included in the research. When the purposive sampling technique had been exhausted, the researcher decided upon snowball sampling, with potential participants being volunteered by existing participants, colleagues and/or fellow researchers, to gain the rest of the participants. ${ }^{35}$ The two sampling techniques resulted in a sample of 14 participants, including, individuals employed by or volunteering with Non-Governmental Organisations (NGOs) and charities $(n=10)$, law enforcement agencies (the police, $n=2)$ and legal professionals $(n=2)$. The current sample was selected as it reflects the multi-faceted and multi-disciplinary nature of those professionals who are engaged in practice, policy, research and the reporting of people trafficking in the UK. Therefore, allowing for a better rounded, more indepth and more applied understanding of professional attitudes to the realities of human trafficking and the role that technology, especially mobile phone technology, plays in this. 


\section{Materials and procedure}

Each interview lasted approximately one hour, being conducted in accordance with the ethical research guidelines set out by the British Psychology Society (BPS) ${ }^{36}$ and the British Society of Criminology (BSC). ${ }^{37}$ All the interviews followed a similar format, with the researcher introducing each topic area, allowing the participants to respond in as much depth as they wanted, often with follow-up questions. In conjunction with this, the researcher allowed the participants the opportunity to discuss any issues they thought pertinent during and at the end of the interview. The interviews were mainly participant focused and participant led. ${ }^{38}$ The interview topics were developed prior to the start of the interviews from ideas and issues developed out of the literature as well as in regard to the aims of the research-these were not an exhaustive list. Although there were commonalities across all the interviews groups, sub-groups and participants (i.e. the access that trafficked people have to mobile phone technology, internet technology, their understanding of and use of technology as well as how technology may be used to combat trafficking and related crimes), there were also group and/or participant specific questions. This approach allowed the participants to talk freely and in depth about their experiences relevant to the research area. Post transcription the participants were contacted, as much as possible, to inquire if they wished to check the transcript of their interview and/or have a copy of their interview transcript; some agreed, but the majority did not.

\section{Data analysis}

The data was then examined via qualitative content analysis, ${ }^{39}$ or what can sometimes be called thematic qualitative analysis. ${ }^{40}$ This approach was selected because it fits with the exploratory aims and objectives of the current research, in that it allows the researcher to confirm what is already known on a topic ${ }^{41}$ to settle disagreements between specialists, ${ }^{42}$ and to reflect the attitudes, interests and values of population groups. ${ }^{43}$ During the thematic content analysis the researchers read each interview transcription independently, highlighting and commenting on important ideas and quotes from each participant, which allowed for the

36 British Psychological Society, 'Code of Ethics and Conduct' (August 2009), available at http://www.bps.org.uk/what-we-do/ethics-standards/ethics-standards, accessed 15 April 2013.

37 British Society of Criminology, 'Code of Ethics', available at http://britsoccrim.org/ codeofethics.htm, accessed 15 April 2013.

38 T. Mason, Qualitative Research in Action (Sage: London, 2002).

39 K. Krippendorff, Content Analysis: An Introduction to its Methodology, 2nd edn (Sage: London, 2004); M. B. Miles and A. M. Huberman, Qualitative Data Analysis: An Expanded Source Book, 2nd edn (Sage: London, 1994); K. A. Neuendorf, The Content Analysis Guidebook (Sage: London, 2002).

40 U. Flick, An Introduction to Qualitative Research, 4th edn (Sage: London, 2009).

41 N. C. Leites and I. de S. Pool, On Content Analysis: Library of Congress, Experimental Division for Study of War-Time Communications, Document 26 (1942), cited in Krippendorff, above n. 39 at 45.

42 Ibid.

43 B. Berelson, Content Analysis in Communication Research (The Free Press: New York, 1952), cited in Krippendorff, above n. 39 at 45-6. 
establishment of a series of themes. Once these preliminary themes were established the researcher re-read each interview again to see how it related to each of the themes, consequentially leading to the expansion, updating and recategorisation of some of the themes. ${ }^{44}$ This resulted in a finalised version of themes which accurately reflected the participants' perceptions and understandings of the relationship between trafficking and technology. The themes where then contextualised in terms of how they related to the other themes, the overall findings from the research, the existing literature and to the individual participants as well as related groups. Throughout the qualitative data analysis care was taken to ensure that the themes established themselves, ${ }^{45}$ particularly via the use of other researchers to independently analyse and verify the main researchers findings.

\section{Results}

The research produced three interconnecting and distinct themes around professional understandings of and attitudes to the role of mobile phone and internet technology in human trafficking:

1. human trafficking as a business and mobile phones as a part of that business;

2. use of technology as a means of control, fear and punishment by traffickers; and

3. use of technology as a crime prevention tool.

The emergence of these themes indicates that professionals believe that traffickers use technology as a way to control and manipulate victims at all stages of the trafficking process (i.e. abduction, transporting, selling/ exchanging victims and throughout their forced labour). Furthermore, mobile phones are used as a means of communication between traffickers, in order to facilitate the 'business' element of trafficking and reflecting the involvement of organised crime groups.

Although victims of trafficking may have access to technology, sometimes high-end technology such as smartphones, depending on what they were trafficked for (i.e. drug production and distribution, high-end prostitution) and their relationship with the traffickers, the trafficker will, in many cases, ultimately have full access and total control of said technologies. Furthermore, the level of coercion and control exercised over victims by traffickers means that even where access to mobile phone and internet technology is possible, the victim is unlikely to make contact with an outside party in order to ask for help.

Nonetheless, based upon participant responses, there does appear to be some scope for the use of technology as a crime prevention tool in the fight against trafficking, be it through an app aimed at victims, or an app aimed at professionals, in order to aid, for example, identification of a

44 E. Murphy and R. Dingwall, Qualitative Methods in Health Policy Research (Aldine de Gruytes: New York, 2003).

45 R. H. Hycner, 'Some Guidelines for the Phenomenological Analysis of Interview Data' (1985) 8 Human Studies 279. 
victim as 'trafficked' as opposed to being incorrectly viewed as 'just another smuggled migrant'.

\section{Human trafficking as a business and mobile phones}

The majority of participants referred to trafficking as a business, and as such mobile phones are an essential business tool in the modern era. The participants felt that in many ways this 'business' approach to explaining trafficking meant that we are better able to understand why mobile phones are more prominent in this area rather than other forms of technology, such as PCs and laptops.

[access to technology is] ... almost universally through a mobile phone because it's, this is all about making money, this is all about operating, effectively what's a business which is spread across wide areas, so the mobile phone is just a piece of effectively business technology that's crucial to control, to communicate and make arrangements about other criminal activities or to meet up to hand over the proceeds. So mobile phone use is heavy ... computers such as desktops rarely found, rarely seen, a few laptops but then again more up on the gang member's side than on the victims of trafficking side. (Participant 3, Law Enforcement Agency)

The participants indicated that mobile phones were used by traffickers in order to maintain contact with each other, in order to facilitate the business 'transactions' and stay in touch with transnational 'partners' and other traffickers who remained in the country of origin.

What we do find with the traffickers, however, is that they would generally have two sim cards, they'll have a local one for keeping cost down for ringing within Europe, but then they'll plug in their existing, in my case in one of my investigations Romanian sim card, because that's a number that's known to, that they're known to use to guys back home. (Participant 3, Law Enforcement Agency)

The participants indicated that access to old, outdated and/or low-end mobile phones were more common for victims, but that this really depended on the nature of the work that the victim was being coerced into doing. The range of phones referred to by participants included the most basic and much more modern, advanced handsets with internet capabilities. The participants indicated that people trafficked for the purpose of sexual exploitation were more likely to have access to mobile phones when compared with people who are trafficked for forced labour. It was argued by participants that this was related to a greater need for frequent contact between the trafficker and the victim, or the victim and 'punters' (in the case of trafficking for sexual exploitation), as well as the need to seem integrated into society and portray a degree of 'normality'.

... they are just given bog standard pay as you go, cheap phones so that they can be phoned and told, you have to be at this place to meet this client at this point you have to phone me to come and pick you up when you finish. (Participant 2, Legal Professional)

... some people you know have a Blackberry or you know have more updated phones ... but the majority of women I'm working with it's 
probably quite a basic phone ... (Participant 9, Non-Governmental Organisation)

What we have found is young teenage boys who are more independent can have smartphones but generally the phones we find are old, second-hand, stolen among the lower level victims. (Participant 3, Law Enforcement Agency)

This reiterates previous comments from the participants, as these phones are given to the victims by the traffickers so that they can monitor and communicate with them; therefore the mobile is a business resource and not a personal one.

... these phones have been already set up by traffickers so that they control if the girl doesn't call, contact the clients, if they contact anyone else apart from these men, if you know what I mean. (Participant 13, NonGovernmental Organisation)

... yeah they had access themselves, mobile phones but that was very clearly about ... um . . . for one of the women it was when she was moved to another place, it was to keep in contact with the trafficker about where she was going, when she was going out, different things. (Participant 9, Non-Governmental Organisation)

Evidently, mobile phones are used to maintain contact with victims in order to facilitate their exploitation, particularly in respect to victims of sex trafficking. Ease of contact is of particular importance here, as sex trafficking is highly lucrative, ${ }^{46}$ and three-way communication between victims, traffickers, and clients/punters is necessary to facilitate the business and generate revenue. Stephen Kavanagh, Deputy Assistant Commissioner of the Metropolitan Police Service, states that '[m]obile phones and other devices are increasingly being used in all levels of criminal activity' ${ }^{47}$ Clearly, mobile phones are increasingly becoming a fundamental part of the 'business' of human trafficking. This is intuitive given the long-distance, complex logistics, the need for secrecy and the rapid reaction often needed as part of the everyday logistics of trafficking operations.

The possession of a mobile phone by a trafficked victim does appear to have the effect of portraying a degree of autonomy, normality, and may be seen as an indication that an individual has, in fact, not been trafficked, and is integrated into normal society. This is because the perception of the 'perfect' trafficked victim as the female who is trafficked for sexual exploitation, locked away from the world, ${ }^{48}$ does not leave room for personal possessions such as a mobile phone-removal of personal possessions is seen as a prevalent indicator of the existence of human trafficking. Guidance as to 'indicators' from the UK Border

46 See Malarek, above n. 3.

47 D. Lee, 'Met Police to extract suspects' mobile phone data', 17 May 2012, available at http://www.bbc.com/news/technology-18102793, accessed 15 April 2013.

48 R. Uy, 'Blinded by Red Lights: Why Trafficking Discourse Should Shift Away from Sex and the "Perfect Victim" Paradigm' (2011) 26 Berkley Journal of Gender, Law and Justice 204. 
Agency, ${ }^{49}$ for example, includes 'Passport or documents held by someone else' and 'Limited social contact'-possession of a mobile phone seems counter-intuitive to a finding of an individual as 'trafficked' when indicators such as this are rigidly adhered to. However, it must be conceded that there are many other indicators to be taken into account, and so it does not necessarily follow that possession of a phone creates an absolute bar to a finding of 'trafficked' as opposed to 'not trafficked'.

Consequently, this research may have ramifications for the identification and treatment of trafficked victims. Recent case law ${ }^{50}$ has indicated that possession of a mobile phone may be incorrectly taken as indicative that an individual has not been trafficked, due to the level of assumed autonomy associated with having possessions such as phones. This is incongruent with the research findings, which clearly demonstrate that, rather than traffickers withholding phones from victims due to fear that they will use them to call for help, they are in fact making use of mobile phones and even supplying victims with them in order to facilitate contact and business transactions with increased ease. Beliefs and assumptions such as are evident in $R \mathrm{v} N$ and $L E$ are not only dangerous, but misinformed, and could lead to adverse outcomes as regards conclusive decisions being reached as to whether or not any putative victim has in fact been trafficked.

Furthermore, as the participants indicated, traffickers use technology to maintain contact with one another, so that they can pass information between them while in different locations or countries, ${ }^{51}$ thereby facilitating the 'business' of dealing in human commodities. This seems intuitive, given that mobile phones are widespread, easily accessible and nondescript in Western society as most people have access to one. ${ }^{52}$ The corollary is that they are an effective means for facilitating quick and easy contact with victims of trafficking as well as other traffickers. This underpins the oft-cited links with organised crime which are evident in human trafficking, highlighted by the fact that the United Nations Trafficking Protocol is annexed to the United Nations Organised Crime Convention-clearly these factors (trafficking and organised crime) are not mutually exclusive. The involvement of organised crime groups is increasingly identified as a factor influencing trafficking activity. Brussa identifies various reasons for the continual rise in trafficking, including principally '[t]he enormous profitability of exploiting women as prostitutes motivating individuals and organized crime networks to engage in the trade in women'.$^{53}$ The role of organised crime groups involved in human trafficking-in Europe and globally-is facilitated by greater

49 Home Office/UK Border Agency, Enforcement Instructions and Guidance, Chapter 9-Identifying Victims of Trafficking, available at http://www.ukba.homeoffice.gov.uk/ sitecontent/documents/policyandlaw/enforcement/oemsectiona/chapter9?view=Binary, accessed 15 April 2013.

$50 R \mathrm{v} N$ and LE [2012] EWCA Crim 189.

51 See McCartan and McAlister, above n. 18.

52 Mobilethinking, above n. 21.

53 L. Brussa, 'Survey of Prostitution, Migration and Traffic in Women: History and Current Situation'(1991) 91(2) Eur Consult Ass 42. 
global engagement; improved communication and travel enhance the opportunities for involvement in human trafficking and the resulting financial gain. Due to the transnational nature of many instances of trafficking, an inherent feature is that it involves more than one, or even several, jurisdictions. Organised criminal gangs control much of the activity, so that the use of criminal law to counteract these activities is highly desirable, while the obstacles to dealing with transnational organised crime are substantial. For law enforcement purposes, the intelligence held on mobile phones supplied to victims (call logs and text messages) as well as that on the phones used by traffickers, could prove significantly useful in combatting human trafficking, identifying victims, and prosecuting traffickers and exploiters.

\section{Use of technology as a means of control, fear and punishment by traffickers}

All of the participants discussed the use of technology as an essential part of the relationship between the traffickers and their victims. The participants stated that technology was used, in the main, to communicate with and control victims of trafficking, and to monitor their activity and whereabouts. Participants stated that those threats were not only levelled at the victims themselves, but also to their families, and that these threats were not only of physical violence, but also to reputation.

... . and so if the issue is I'll go and be exploited or my sister will be killed for example, and we'll choose to go back and the threats of violence and intimidation are quite real. (Participant 2, Legal Professional)

... we have had it where females have rung us and said, I need to get out of this but if I don't stop he's going to tell my family . . . (Participant 5, Law Enforcement Agency)

Certainly you know obviously some women you know they're just watched constantly but one of the women I was working with she was, she was moved to a different part of the country and a lot of it was through mobile phone. She would need to phone when she was going out and let the trafficker know where she was going and phoning to tell him when she was coming back ... (Participant 9, Non-Governmental Organisation)

The traffickers' level of control, and therefore the reality of the threats, is heightened by the fact that they place restrictions on the mobile phones which they supply their victims with. These restrictions can take many forms including, but not limited to, making sure the phones only receive incoming calls, constantly checking the phone/sim for information (i.e. stored numbers, past calls/texts), disabling high functions (i.e., internet, Bluetooth, etc.) and removing the victims own mobile phone from them at the point of first contact. This means that that the victims cannot use the mobile phones, and/or related technology, in an alternative fashion or if they do so then the trafficker will know about it.

... if the trafficker finds out you've been using your phone, the girl has been using her phone, for example calling somewhere, so he will change 
the number straight away ... (Participant 13, Non-Governmental Organisation)

... on the whole it's a closed circuit between them and him. (Participant 11, Non-Governmental Organisation)

There is no money on that phone so trafficker calls you only ... (Participant 13, Non-Governmental Organisation)

Therefore, the traffickers by controlling the victims' means of, and access to, communication in conjunction with the threats that they level means that the victim is afraid and unable to approach anyone for help. The corollary is that the victims are placed in a situation of complete dependence upon the traffickers with many of the participants drawing analogies between being a victim of trafficking and being a victim of domestic violence. This is compounded by several factors. Primarily, the fact that the traffickers encourage a mistrust of the authorities, as well as the fact that there may also be pre-existing mistrust of authorities if the victim originates from a country where the authorities are complicit or at least tolerant of trafficking. Furthermore, the traffickers threaten to shame the victims in front of their families, and weaken their resolve by indicating that they are stupid, unimportant and will not be believed.

I don't think that had occurred to her that she could use that (mobile phone) and also just the methods of control that he was using . . . at times later on in the five years on or whatever, she was allowed to go out and she could go out and do shopping and she did attend the doctors appointments and, but the level of control that he had over her that she just felt that she couldn't tell anybody . . . So I don't think it occurred to her at any point to ... (use the mobile phone) (Participant 10, Non-Governmental Organisation)

... the control mechanisms to fear the violence of threats, physical injuries and are such that the individual is broken and frequently is to, it's I mean I'm trying to sort of analogise it here and I guess the best way I can, I consequently come back to this analogy, its battered wives syndrome ... you see the domestic violence going on over a period of time with you know intelligent people being subjected to domestic violence and you constantly look at it and you constantly question it, but why didn't she just walk out and it's more to do with psychological control mechanisms used by the traffickers. (Participant 4 , Charity)

The impact of the coercion perpetrated on the victims by the traffickers is also compounded by the heterogeneous nature of the victims. The participants stated that individual differences in victiminology demographics, country of origin, understanding of technology, adaptability to the UK and understanding of, as well as role, in their situation is important in how they use the technology to which they have access. Therefore, victims who come from rural, uneducated and impoverished backgrounds may be more unlikely to have had access to technology previously; therefore they are less likely to engage with it or understand how to utilise it effectively if given the opportunity.

... some of the stories of the women we've worked with are, they are coming from deepest darkest Africa, so actually you are talking about kind 
of potentially third world living, no mobiles phones, etc. for communication devices aren't naturally part of their life, whereas when you then go to eastern Europe that actually, everyone kind of has a mobile phone anyway ... (Participant 12, Non-Governmental Organisation)

To be honest the ... you know people you know when you come from higher, high areas of poverty ... if you're from I don't know, Sierra Leone, you know sometimes you're not going to have a phone and you're not going to have certain things. (Interview 9, Non-Governmental Organisation)

The professionals indicate that the potential impact of access to a mobile phone, as well as other forms of technology, is undermined and affected by the coercive practices and mechanisms that traffickers use to control their victims. Outright force and violence, which constitute more ostensible signs of abuse, are not always used by traffickers. Psychological coercion, for example, is employed to maintain a level of control over trafficked victims which is comparable to that used against a domestic abuse/violence victim, for example, in the domestic case of $R \mathrm{v}$ Roci (Lorenc) ${ }^{54}$ restriction of liberty through the use of threats to the trafficked women was evident. Similarly, in the US case of United States $\mathrm{v}$ Jimenez-Calderon, ${ }^{55}$ the trafficked women were not allowed to leave the house or even speak to each other. Hence, the participants indicated that the level of coercion exerted over the victims is so great, that this significantly reduces the likelihood of external contact being made. This highlights the difficulties inherent in victim identification (i.e. as 'trafficked' rather than 'not trafficked') because more subtle, less ostensible signs of coercion are more difficult for professionals charged with identifying victims to pick up on. Once again, the link with domestic abuse/ violence is apparent, which is defined by the UK government as 'any incident of threatening behaviour, violence or abuse [psychological, physical, sexual, financial or emotional] . . . ${ }^{56}$

It is not uncommon that threats to family members are reported by trafficked victims. ${ }^{57}$ The definition of 'human trafficking' provided within the UN Trafficking Protocol, the Council of Europe Trafficking Convention and the 2011 Trafficking Directive refers to 'abuse of a position of vulnerability' (i.e. abuse of the victim's position of vulnerability, by a trafficker) which includes vulnerability which may be, inter alia, 'family-related'. ${ }^{58}$ The participants indicate that the trafficker

54 [2005] EWCA Crim 3404, [2006] 2 Cr App R (S) 15.

55135 Fed Appx 562 (3d Cir 2005), see UNODC, http://www.unodc.org/cld/en/case-law/ usa/2006/united_states_v.jimenez-calderon_et_al..html, accessed 15 April 2013.

56 Crown Prosecution Service, CPS Policy for Prosecuting Cases of Domestic Violence, (March 2009) 10, available at http://www.cps.gov.uk/publications/docs/ domesticviolencepolicy.pdf, accessed 15 April 2013.

57 K. Jackson, J. Jeffery and G. Adamson, 'Setting the Record: The Trafficking of Migrant Women in the England and Wales Off-street Prostitution Sector' (Project Acumen: ACPO Migration and Associated Matters: August 2010), available at http:// www.acpo.police.uk/documents/crime/2010/201008CRITMW01.pdf, accessed 15 April 2013.

58 Explanatory Report to the Council of Europe Convention on Action against Trafficking in Human Beings, para. 83 (adopted 3 May 2005, entered into force 1 February 2008) Warsaw, 16.V.2005. Council of Europe Treaty Series-No. 197. 
abuses the vulnerability of the victim through threats to family members in this manner, as a method of retaining control over the victim, and such threats are clearly a factor affecting the decision of victims whether or not to make contact ${ }^{59}$ and consequently whether or not to use the mobile phone in their possession to make contact to alert their family to their situation of control and abuse.

Similarly, threats to tell the family that, for example, the victim has worked in the sex trade are commonplace among victims and therefore remain a strong means of psychological control/coercion. ${ }^{60}$ Such threats can therefore prevent victims with access to mobile phone and/or internet technology from making contact with an external party in order to request aid, as a need for simple 'rescue' is not the only factor influencing the decision whether or not to make contact. Clearly, a complex means of continued coercive practice is employed.

Finally, trafficked victims come from a vast range of countries, regions and backgrounds. ${ }^{61}$ Country of origin, as well as conditions of poverty or lack of education, mean that understanding of technology may be more limited. Therefore, victims from such backgrounds may be more likely to remain in their trafficked situation.

This means that people who have been trafficked are vulnerable, and are therefore victims, on a multitude of fronts given what is known of their demographics and background. ${ }^{62}$ This multiple victimhood, although problematic, means that professionals can use other approaches or models of engagement around domestic and interpersonal violence in mainstream, as well as Black and ethnic minority communities, across the UK with these individuals to remove them from their situation. Once this has been done it also means that there are also more potential avenues for trafficked individuals to be helped to cope with their experience by charities or the state through a variety of social, psychological and health services opened up by their direct as well as indirect victim status.

\section{Use of technology as a crime prevention tool}

The participants were quite conflicted on the effectiveness and usefulness of mobile phone technology as a means to help victims of trafficking to escape their situation. Participants were split into two camps: one which stated that technology has been known to help people escape from trafficking situations; and the other being that because of the fact that access to technology is so closely regulated-if there is any access at all-that it would be an ineffective tool.

59 Serious Organised Crime Agency, 'The UK Human Trafficking Centre, Frequently Asked Questions' (2012), available at http://www.soca.gov.uk/about-socalabout-the-ukhtc /frequently-asked-questions, accessed 15 April 2013.

60 L. Brown, Sex Slaves: The Trafficking of Women in Asia (Virago Press: London, 1999).

61 Aronowitz, above n. 1; Europol, above n. 16.

62 United Nations Inter-Agency Project on Human Trafficking, 'Human Trafficking Background Information: What are the risk factors contributing to human trafficking that we should aim to reduce?', available at http://www.no-trafficking.org/ resources_background_risks.html, accessed 15 April 2013. 
... there's been one occasion where someone has lent a decent mobile phone and enabled the woman to call home, who then notified the police in their own country, passed it onto the UK police force. (Participant 12, Non-Governmental Organisation)

I think the fear of being caught or that person you know looking on their phone and seeing that they've called someone or you know of their position of being illegal or the fear of the police or that there's just so many levels of fear that I think it's like either a crisis thing that happens where they know, yeah I can dial 999 or to, I don't know some way that they could feel that you know they wouldn't be found out of having contacted someone. (Participant 10, Non-Governmental Organisation)

However, despite these divisions the participants did not dismiss out of hand the possibility that technology could have some impact. One of the possible roles for technology in preventing and/or responding to trafficking was the development of an 'app' that could be downloaded and used by the victim. Many of the participants were critical of this, saying that if the majority of victims of trafficking did not have smartphones, how could they access this resource? Also, if the victim's first language were not English, how could that victim identify the app on the relevant marketplace and then download and use it? These issues were exacerbated when the age, education and adeptness of the victim to technology was also considered. Furthermore, the app would have to be disguised so that traffickers could not identify it; therefore could victims identify it online?

... so potentially then, a need exists for it, now you could disguise that because again you wouldn't want signposts with 'download this human traffic app', so you could generalise it. (Participant 3, Law Enforcement Agency)

... there's so many ifs and buts you know . . . I just don't know how people would ever know about it ... I think it's just you know the whole kind of Western perception of a phone app for people who are trafficked. (Participant 9, Non-Governmental Organisation)

Despite these complaints the participants felt that a one-stop, online easily accessible resource could be beneficial, but they were not sure what it would look like or how it would work.

Well wouldn't it be handy to have an app that someone could draw down to give them instructions on where to go for help, so that would be a huge app development. (Participant 3, Law Enforcement Agency)

I think there could be a general app that could be an SOS app that would, for a variety of things that maybe take somebody straight through to crime stoppers or some Interpol type number. (Participant 8, Non-Governmental Organisation)

Some of the participants felt that apps, resources, developed for practitioners/professionals would be beneficial. These would be apps developed to educate, inform and assist frontline staff in understanding and therefore better responding to human trafficking and the related law enforcement issues. 
I think apps probably be good for front-line staff and front-line support services to kind of go, oh I think I've found someone, what I do ... (Participant 12, Non-Governmental Organisation)

... around the NGO sector for police officers there are a number of apps being developed to instruct them on human trafficking. (Participant 3, Law Enforcement Agency)

Although the participants indicate a level of concern about the realistic impact of mobile phone technology, especially apps, to counter trafficking, they believe that it should not be immediately discounted suggesting that it may simply be another tool in the anti-trafficking toolkit. Therefore technological developments can be part of the solution to the problem of trafficking, ${ }^{63}$ highlighting that law enforcement, as well as traffickers, can effectively adapt technology to suit their own needs. Guidance issued to prospective migrants by SOCA states that such persons should '[h] ave a safety net. Leave details with family and have prearranged contact patterns and code words or phrases that can be given to family if you are under duress, without arousing suspicion if traffickers are listening' ${ }^{64}$ The points raised in this guidance are exactly the kind of thing that an app may be designed and used for, and closely mirrors that provided for by the development of the 'Safe Trip' app referred to earlier in this article. ${ }^{65}$

The prevailing concern was that apps would have to be well hidden or disguised, underpinning the idea that the potential for the app (or similar) actually to cause harm to the victim is a very real issue. ${ }^{66}$ Discovery, by a trafficker, of such an app being used by a victim could lead to very serious consequences for the victim. Thus, the issue of how the app should be presented, where it should be held, and how it should be accessed (i.e. on the device or online) would clearly feature as a factor to be considered at the design stage.

As regards the professionals who come into contact with putative victims, identifying a victim as potentially trafficked is problematic in itself, ${ }^{67}$ as well as the issue of what to do once a suspected victim has been identified. Consequently, an app which instructs those who have come into contact with a putative victim as to what 'indicators' (such as those outlined by the Home Office/UK Border Agency) to look for could be useful, particularly as it could be added to as and when victimology and victim behaviour becomes better understood. Furthermore, such apps would provide another avenue for raising awareness of trafficking amongst those charged with identifying victims and putative victims.

\section{Conclusions}

Overall, this research indicates that mobile phone technology is increasingly being used to facilitate trafficking at all levels of the process (i.e.

63 See Padget, above n. 30.

64 Serious Organised Crime Agency, above n. 59.

65 Guardian Hactivate Event, above n. 31.

66 Latonero, above n. 25.

67 J. Elliott, '(Mis)Identification of Victims of Human Trafficking: The Case of $R \vee O$ ', (2009) 21 Int J Refugee Law 727. 
victim acquisition, transportation and forced labour). Not only are traffickers using mobile phone technology to communicate with each other to facilitate the 'business' of human commodification, but they are evidently also using mobile phones to contact and exploit victims and to maintain a level of coercion and control through persistent contact. This indicates that traffickers, like other transnational and interpersonal offenders, have used adaptions in technology to assist them in developing their offending behaviour. This constant adaptation of traffickers' means of offending and the way that they facilitate their offending means that it is increasingly difficult for the law to respond to, predict or effectively target trafficking in general or in regard to their use of technology.

Although the relationship between technology and law enforcement in respect of combating or preventing trafficking is a problematic one, this does not mean that law enforcement cannot engage with technology on any level to assist in their response to human trafficking. It is now apparent that victims of human trafficking-particularly sex trafficking-do have access to technology, particularly mobile phone technology, which means that this technology could be adapted by law enforcement to assist these individuals escape their situation. The next step is to determine how law enforcement agencies can effectively use technology, particularly mobile phone technology, to assist them in combating human trafficking, whether it is to access the vast array of intelligence held on the mobile phones used for trafficker, for the development of apps for victims, and/or using satellite/network to provide tracking tools to locate victims and offenders.

The overarching conclusion is that access to technology can, for trafficked persons, be a double-edged sword:

... [access to technology is] good in the sense that for women ... it gives them contact with the outside world. It . . can give them a lot of freedom but on the other hand it can also be used to keep constant checks on them, to ... make sure ... that people know where they are and what they're doing ... (Participant 9, Non-Governmental Organisation)

Consequently, resources can be directed at internet/mobile phones in order to help combat this global phenomenon-but various matters have to be taken into account, not least the safety of the victim. 
